\title{
Número de chamada e FRBR: um diálogo norteado por princípios da Organização da Informação
}

\author{
Call number and FRBR: A dialogue guided by principles \\ of the Organization of Information
}

\author{
Camila Mariana Aparecida da SILVA 1 iD 0000-0002-0429-1146 \\ Vinicius de Souza TOLENTINO² (iD 0000-0001-7872-3629 \\ Cristina Dotta ORTEGA ${ }^{1}$ id 0000-0002-9735-7676
}

\section{Resumo}

O número de chamada exerce papel relevante nas bibliotecas, visto que a ordenação de documentos se configura como proposta de leitura da coleção, estabelece o elo entre o registro no catálogo e o local que o documento ocupa na coleção para fins de acesso e contribui para a gestão dos usos do espaço. A partir do final do século XX, a International Federation of Library Associations and Institutions promoveu estudos que culminaram em diretrizes para processos, produtos e instrumentos documentários, destacando-se o modelo conceitual Functional Requirements for Bibliographic Records. O presente artigo tem por objetivo analisar a construção do número do livro - parte final do número de chamada - em associação aos atributos das entidades do Grupo 1 do Functional Requirements for Bibliographic Records. Para a fundamentação teórica, aborda os trabalhos de Cutter, Barden, Lehnus, Satija, e o Functional Requirements for Bibliographic Records, assim como os trabalhos mais recentes de Moreno e Ortega. Como metodologia, realiza pesquisa exploratória por meio de revisão de literatura que resulta no cotejamento do número de chamada e do Functional Requirements for Bibliographic Records baseado na decomposição de exemplos. Conclui apontando a atualidade do número de chamada como modelo operacionalizável para a ordenação de documentos e como construto elaborado a partir de princípios que apresentam correlação com o Functional Requirements for Bibliographic Records.

Palavras-chave: FRBR. Número de chamada. Número do livro. Ordenação da coleção. Organização da informação.

\begin{abstract}
Call number plays a relevant role in libraries, since ordering of documents is configured as a proposal for reading collections, establishes the link between catalog entry and the place document occupies in the collection for access purposes and contributes to the collection management of space uses. From the late twentieth century, International Federation of Library Associations and Institutions promoted studies that culminated in guidelines for documentary processes, products and instruments, notably Functional Requirements for Bibliographic Records conceptual model. The purpose of this article is to analyze the construction of book number - the final part of call number - in association with attributes of the entities of Group 1 of Functional Requirements for Bibliographic Records. For theoretical foundation, it approaches works of Cutter, Barden, Lehnus, Satija and Functional Requirements for Bibliographic Records, as well as Moreno's and Ortega. As a methodology, it performs exploratory research through literature review that results in the examination of the call number and the Functional Requirements for Bibliographic Records based on the decomposition of examples. It concludes by pointing out the actuality of call number as a workable model for ordering of documents and as a construction elaborated from principles that have correlation with Functional Requirements for Bibliographic Records.
\end{abstract}

Keywords: FRBR. Call number. Book number. Collection arrangement. Organization of information.

1 Universidade Federal de Minas Gerais, Escola de Ciência da Informação, Programa de Pós-Graduação em Ciência da Informação. Av. Antônio Carlos, 6627, 31270-901, Pampulha, Belo Horizonte, MG, Brasil. Correspondência para/Correspondence to: C. ORTEGA. E-mail: <ortega@eci.ufmg.br>.

2 Universidade Federal do Estado do Rio de Janeiro, Centro de Ciências Humanas e Sociais, Departamento de Biblioteconomia. Rio de Janeiro, RJ, Brasil. Recebido em 20 de julho de 2018, reapresentado em 6 e de fevereiro de 2019 e aprovado em 26 de fevereiro de 2019.

Como citar este artigo/How to cite this article

Silva, C.M.A; Tolentino, V.S.; Ortega, C.D. Número de chamada e FRBR: um diálogo norteado por princípios da Organização da Informação. Transinformação, v.31, e180052, 2019. http://dx.doi.org/10.1590/2318-0889201931e180052 


\section{Introdução}

A Organização da Informação tem como escopo primordial a elaboração de sistemas de informação que visam subsidiar o uso qualificado da informação, considerando as particularidades dos usuários, os objetivos institucionais em questão e as características da coleção de documentos. Para tanto, ela articula processos e instrumentos que passam a compor sistemas e serviços. Esses, norteados por princípios comuns, irão conferir identidade e unidade às propostas ofertadas aos usuários. Contudo, via de regra, essas propostas são concebidas ou analisadas à revelia deste arcabouço conceitual e podem resultar em produtos pouco consistentes ou, ainda, ineficazes ou redundantes em termos de sua estrutura.

Segundo Svenonius (2000), a Organização da Informação se apoia em uma base intelectual advinda de uma ideologia formulada em termos de propósitos e princípios, da formalização de processos documentários, de conhecimentos fundados na pesquisa e da construção de disciplinas. Strout (1956) e Sordet (2016), ao trabalharem a história dos catálogos e da catalogação, explicitam que distintas práticas de Organização da Informação foram elaboradas com o intuito de criar sistemas de informação destinados a atender demandas locais e/ou nacionais. Calenge (2010), ao discutir a ordenação dos documentos em mobiliários, argumenta que não se trata exclusivamente de conceber um sistema para a disposição dos itens, mas de se pensar sobre a significação do espaço ordenado em sua disposição e articulação com a política documentária.

Tendo por base o trabalho de Svenonius (2000), no caso das pesquisas de Strout (1956) e Sordet (2016), explicita-se o modo como essas práticas são formalizadas em processos e trazem consigo contribuições para o desenvolvimento de novos instrumentos que subsidiam a construção dos produtos documentários. No trabalho de Calenge (2010), ressalta-se a dimensão intelectual fundada na definição de princípios e objetivos que norteiam a elaboração desses mesmos produtos.

O número de chamada, enquanto produto documentário, exerce papel relevante na elaboração de sistemas de informação bibliográfica, visto que conforma uma proposta de leitura da coleção, estabelece o elo entre o registro do documento na base de dados e o local que o documento ocupa na coleção para fins de livre acesso, e ainda contribui para a gestão no tocante aos usos do espaço. Esse modelo resulta em modos de acesso pretendidos que podem potencializar certos usos pressupostos das coleções, fomentando a apropriação da informação, especialmente nos contextos em que a especificidade e a exaustividade das coleções são características marcantes.

A partir do final do século XX, a International Federation of Library Associations and Institutions (IFLA) promoveu estudos e debates norteados pelos desafios relacionados à aplicabilidade das tecnologias de informação e comunicação incorporadas pela área. Os estudos produzidos desde então foram debatidos por diversos especialistas, culminando em diretrizes para processos, produtos e instrumentos documentários destinados às bibliotecas, centros de documentação e demais espaços que atuam com a guarda, registro, preservação e disponibilização de documentos. Dentre as diretrizes elaboradas, destaca-se o modelo conceitual Functional Requirements for 2 Bibliographic Records (FRBR) que impactou diretamente os processos de representação realizados no contexto digital das múltiplas tipologias e suportes documentais, mas que não resultou em uma absorção disseminada de seus princípios na estruturação dos catálogos.

Os catálogos, produto de práticas documentárias, disponibilizam uma descrição estruturada de uma coleção, materializam um discurso sobre ela e são ferramentas para a difusão de um saber textual. Essas funções não são concebidas ao acaso, embora possam ser conduzidas inadvertidamente, haja vista que as práticas documentárias são orientadas por uma previsão de uso de informações. Desse modo, os catálogos e os resultados de busca apresentados aos usuários buscam refletir as necessidades do público em questão.

Nesse sentido, o presente artigo tem por objetivo explicitar a correlação que se estabelece entre os elementos constituintes do número de chamada, conforme proposta apresentada por Cutter (1908; 1962), e os 
atributos das entidades do Grupo 1 do modelo conceitual FRBR (International Federation of Library Associations and Institutions, 1998), em busca de aproximações e distanciamentos que permitam colocá-los em diálogo no contexto de princípios básicos do espectro da Organização da Informação. A proposta consiste, portanto, em apontar os elementos estruturantes que coadunam conceitos norteadores aos processos de Organização da Informação, explicitando como a estrutura preconizada pelos FRBR encontra ressonância na disposição espacial da coleção a partir do número de chamada, embora tenham sido propostos em períodos bastante distantes.

\section{Procedimentos Metodológicos}

Realiza-se uma pesquisa de cunho exploratório oportunizada pelo levantamento histórico conceitual do número de chamada, em revisão de literatura a partir dos trabalhos de Cutter (1908; 1962), Barden (1937), Lehnus (1978), Satija (1990) e, mais recentemente, obra nacional de Ortega, Silva e Santos (2016) dedicada à conceituação, historicização e instrumentalização do modelo. Destaca-se, neste conjunto, a abordagem de Cutter como proposta voltada à operacionalização do número de chamada, especialmente no que diz respeito à elaboração do número do livro e, nele, a conversão de sobrenomes de autores em notações alfanuméricas. Em seguida, apresenta-se o estudo do Grupo 1 do FRBR, tendo por base o relatório final do modelo conceitual (International Federation of Library Associations and Institutions, 1998) e sua tradução em português publicado em 2008, assim como os trabalhos de Moreno e Márdero Arellano (2005), Moreno (2006) e na Statement of International Cataloguing Principles (Declaração dos Princípios Internacionais de Catalogação) (International Federation of Library Associations, 2016). Parte-se, então, para a elaboração, decomposição e análise de cinco exemplos ordenados conforme o modelo de número de chamada proposto por Cutter, a fim de atestar a pertinência de sua relação com os FRBR, especialmente no que concerne às entidades do Grupo 1.

\section{Resultados e Discussão}

Tendo em vista a pertinência da análise conceitual para a explicitação dos elementos basilares que aproximam o número de chamada e o modelo conceitual FRBR, a discussão precede a apresentação dos resultados. Conforme os objetivos explicitados e as características da reflexão proposta, o resultado é apresentado como desdobramento da sistematização realizada. Assim, a análise segue no sentido de estruturar uma argumentação capaz de embasar a compreensão articulada entre construtos pertinentes à Organização da Informação, sendo o resultado o percurso desenvolvido a fim de fundamentar e articular os elementos postos em diálogo.

\section{O número de chamada}

Dentre os processos de Organização da Informação realizados no âmbito de bibliotecas, a ordenação de documentos compreende uma série de atividades que, associadas, resultam na "[...] materialização de um arranjo para coleções que será definido com o objetivo de realizar a disposição física dos documentos no espaço" (Silva, 2016, p.32). Essa disposição será orientada pelos objetivos que se busque alcançar e, por isso, deve estar atenta às especificidades da instituição, dos usuários que se espera atender e da coleção a que está relacionada. Consoante o objetivo determinado, certas características dos objetos são observadas a partir dos contextos documentários e servirão de base à proposição de arranjos, constituindo o método que orientará sua estruturação.

A análise efetuada por Ortega, Silva e Santos (2016) aponta que a ordenação de documentos pode ser realizada com base em três diferentes métodos: alfabético, cronológico e sistemático. Cabe ressaltar que um método é definido pela característica documental que será adotada como elemento principal na composição do arranjo, ou seja, por um critério que constituirá o elemento primário para a disposição dos documentos. 
No método alfabético, arranjos são elaborados com base em características dos documentos passíveis de alfabetação e que permitem ordená-los em uma sequência linear A-Z a partir da palavra definida conforme o critério primário, como ocorre, por exemplo, com a autoria ou o título do documento. O método cronológico funda-se pela escolha de características que viabilizam a formação de uma sequência temporal linear para os objetos ordenados, como o ano de publicação do documento ou a sua ordem de entrada na coleção. Por sua vez, o método sistemático se instaura quando da seleção de características estruturadas em um conjunto de classes e subclasses que oportuniza a intercalação de documentos dentro de agrupamentos norteados por esta mesma estrutura e consolidada em arranjo usualmente elaborado para fins de livre acesso aos usuários.

O método sistemático, com frequência, emprega em sua execução sistemas de classificação bibliográfica, como a Classificação Decimal de Dewey (CDD) e a Classificação Decimal Universal (CDU), mas cabe pontuar que é possível utilizar instrumentos distintos, elaborados em contextos particulares, que podem, inclusive, valer-se de estruturas hierárquicas mais simples. Em todo caso, apesar da diversidade das estruturas hierárquicas passíveis de uso, sistemas de classificação bibliográfica constituem-se como matéria básica do método sistemático.

O emprego deste método implica a materialização de sistemas de localização relativa nos quais os arranjos são elaborados de modo a permitir frequentes alterações no posicionamento dos documentos, concomitantemente à incorporação de novos itens e sem alteração da estrutura concretizada (Mann, 1962). Nesses sistemas, os agrupamentos de documentos são formados a partir de certas características de interesse e, dentro destes agrupamentos, estabelecem-se novos critérios que determinarão o modo como os documentos serão organizados internamente. Assim, mesmo com a chegada de novos itens, o usuário pode percorrer livremente a coleção, haja vista a manutenção da inteligibilidade da ordem dada.

O método sistemático permite a associação de características variadas para fins de agrupamento e demanda a adição de atributos complementares para viabilizar a individualização de cada documento dentro do grupo que Ihe foi atribuído. Neste sentido, dentro da tradição anglo-americana de elaboração de modelos de ordenação de documentos para o contexto de bibliotecas, o número de chamada (call number) ocupa lugar de destaque na instrumentalização de sistemas de localização relativa.

As formulações em torno deste modelo tiveram seus primeiros elementos colocados por Dewey, ainda em 1876, e foram sistematizadas por Ranganathan (1967) quase 60 anos depois, numa fórmula que estabelecia a ligação entre três elementos: o número de coleção (collection number), o número de classe (class number) e o número do livro (book number). Essa junção, embora explicitada pela primeira vez por Ranganathan, não pode ser atribuída a ele exclusivamente. Seus elementos, mesmo sem concatenação linear, estavam presentes em propostas anteriores apresentadas por bibliotecários como Cutter, Schwartz, Dewey, Brown e Bliss, que afirmavam ser necessário adicionar à notação extraída do esquema classificatório elementos que auxiliassem na identificação de cada documento no conjunto da coleção.

Deste modo, o número de chamada se estrutura tendo por base os agrupamentos viabilizados pelos sistemas de classificação bibliográfica e, se a partir do número de classe é possível aproximar documentos com características em comum (assunto, tipologia documental, procedência da literatura, entre outros), dentro dos conjuntos faz-se necessário singularizar cada documento a partir de características secundárias, por meio do número do livro. O número de coleção, anteposto ao número de classe, oferece ainda a garantia de que parcelas da coleção sejam mantidas em separado da coleção principal, quando de interesse (Satija, 1990).

Para fins de elaboração do número do livro, a ordenação alfabética dentro das classes, em detrimento da ordenação cronológica, conseguiu significativo destaque, especialmente pelo uso das tabelas de Cutter e de Cutter-Sanborn elaboradas na virada do século XIX para o XX. O número do livro, sob esta perspectiva, é composto pela notação de autor extraída das tabelas de Cutter e pela marca da obra, recurso que permite individualizar as diversas obras de um mesmo autor a partir de seu título, agrupar as traduções, as críticas, comentários e dicionários 
sobre a obra em questão, e, também, as diversas edições e exemplares de uma mesma obra. Esta estrutura permite, então, que todo item tenha um número de chamada próprio que o individualiza dentro da coleção (Ortega; Silva; Santos, 2016).

Outro ponto que merece destaque é o fato de que, na década de 1930, paralelamente ao desenvolvimento dos estudos de Ranganathan, despontaram alguns trabalhos que tinham em vista a instrumentalização do número de chamada para a prática profissional. Esses trabalhos voltavam-se fundamentalmente para a descrição e prescrição quanto à utilização do número de chamada conformado em uma combinação preferencial entre o número de classe, mormente extraído da CDD, e o número do livro baseado no arranjo alfabético estruturado a partir das tabelas de Cutter, usualmente a tabela Cutter-Sanborn. Este é o caso dos livros de Mann (1930) e Barden (1937), publicados pela American Library Association (ALA) na década de 1930, e, posteriormente, na década de 1970, o livro de Lehnus (1978). Embora apresentem detalhamentos sobre as possibilidades de elaboração do número de livro não propostos por Cutter, todos estes autores indicam o uso da tabela Cutter-Sanborn e seguem uma lógica de elaboração da notação bastante aproximada daquela prescrita pelas tabelas Cutter.

Dessa maneira, mesmo considerando a inexistência de um modelo único e aplicável a quaisquer contextos, opta-se pelo exame exclusivo das orientações que acompanham as tabelas Cutter-Sanborn. Cabe ressaltar a penetrabilidade dessa proposta de composição do número do livro, ainda hoje empregado em contexto de bibliotecas e, também, sua centralidade na elaboração do número de chamada enquanto modelo anglo-americano dedicado a dar acesso livre às coleções. No Brasil, por sua vez, o termo 'número do livro' não é adotado, a despeito do uso que se faz dele na construção do número de chamada.

\section{As entidades e atributos do Grupo 1 do modelo FRBR}

O estudo para o desenvolvimento da criação dos FRBR deu-se a partir do objetivo de reestruturar os registros bibliográficos, de maneira a refletir a forma como ocorre a busca pela informação, tendo em vista a diversidade e necessidade do usuário, tipologias documentais, suportes e formatos. O modelo recomenda um nível mínimo de funcionalidade para os registros criados pelas agências bibliográficas nacionais.

Segundo o relatório (International Federation of Library Associations and Institutions, 1998), os FRBR têm como finalidade aprimorar o desenvolvimento e apresentação dos registros bibliográficos no que concerne à estruturação dos dados e, por decorrência, do próprio catálogo. Além disso, foram criados para estabelecer conceitos no que se refere à diversidade de materiais, suportes e formatos representados em bases de dados e simplificar os catálogos automatizados aos olhos dos usuários.

Nos FRBR, adota-se o modelo entidade-relacionamento, que é constituído por três elementos. São eles: as entidades, os atributos e os relacionamentos. 'Entidade' pode ser entendida como "uma categoria abstrata de objetos conceituais" (International Federation of Library Associations, 2016, p.15, tradução nossa). 'Atributos' são um conjunto de características das entidades. Abrangem geralmente uma entidade, incluindo não só as características físicas, mas também aspectos que podem ser caracterizados como informação identificadora (que, em geral, consta na folha de rosto ou capa do documento) (International Federation of Library Associations, 2008, p.47). 'Relacionamentos' são qualquer classe de associações entre os atributos das entidades.

Os FRBR são compostos por dez entidades que se dividem em três grupos. São eles: Grupo 1 - obra, expressão, manifestação e item (esse grupo será aprofundado adiante, visto que o presente artigo tem por objetivo identificar atributos inerentes às entidades que o compõem); Grupo 2 - pessoa e entidade coletiva; Grupo 3 - conceito, objeto, evento e lugar.

A'obra'é a primeira entidade apresentada no FRBR e tem por definição ser abstrata e reconhecida através das realizações individuais ou expressões da obra que só existem na comunhão de conteúdo das diversas expressões da obra (International Federation of Library Associations and Institutions, 1998, p.17). Segundo Moreno e Márdero 
Arellano (2005, p.27), "obra é uma entidade abstrata, uma criação intelectual ou artística distinta". Le Boeuf (2008, p.157) exemplifica o significado dessa entidade com a palavra "livro", como o conteúdo conceitual que subjaz a todas suas versões linguísticas, tanto a original como a tradução; a 'coisa' que um autor pode reconhecer como sua obra, inclusive, por exemplo, em uma tradução japonesa e ainda que não fale japonês e não seja, portanto, responsável pelo texto japonês.

A 'expressão', para a International Federation of Library Associations and Institutions (1998, p.19, tradução nossa) é: "[...] uma realização intelectual ou artística de uma obra sob a forma de notação alfa-numérica, musical ou coreográfica, som, imagem, objeto, movimento etc, ou qualquer combinação de tais formas. Uma expressão é a forma intelectual ou artística específica que assume uma obra a cada vez em que é realizada".

De acordo com Moreno e Márdero Arellano (2005, p.27), "a entidade expressão de uma obra é a realização intelectual ou artística específica que assume uma obra ao ser realizada, excluindo-se aí aspectos da alteração da forma física".

A expressão de uma obra é materializada por meio de outra entidade, a 'manifestação'. Esta entidade compreende qualquer objeto abordado como documento. A manifestação representa todos os objetos físicos que carregam as mesmas características, no que diz respeito ao conteúdo intelectual e à forma física. A manifestação "pode conter uma coleção de obras, uma obra individual ou uma parte de uma obra" (International Federation of Library Associations, 2016, p.16, tradução nossa).

A quarta e última entidade do Grupo 1 é o 'item,' um "único exemplar de uma manifestação" (International Federation of Library Associations, 2016, p.16, tradução nossa). O item é físico, o que inclui o meio digital, porque é a exemplificação da manifestação. Há casos em que um item pode ser composto por mais de um objeto físico.

Dentre as entidades do Grupo 1, apenas as duas últimas refletem a forma física, uma vez que se referem aos elementos concretos do documento, diferentes das duas primeiras que se definem pelo conteúdo intelectual ou artístico do documento. Através dos atributos, podemos estabelecer distinções entre uma obra e outra, e entre uma obra e sua expressão e/ou manifestação.

O modelo FRBR apresenta atributos para cada uma de suas entidades, mas para efeito deste trabalho, apenas aqueles que se refletem na estrutura do número do livro serão explicitados. Para a entidade obra, serão apresentados título da obra e forma da obra. Na entidade expressão, serão comentadas a forma da expressão e a língua da expressão. Já os atributos examinados da entidade 'manifestação' são: indicação de responsabilidade, indicação de edição, data de publicação. E, por fim, o atributo identificador do item na entidade 'item'.

O 'título da obra' consiste na palavra, frase ou grupo de caracteres que designam a obra. A 'forma da obra'é a classe a que a obra pertence, por exemplo, novela, drama, poema, ensaio, biografia etc. (International Federation of Library Associations, 2008, p.50).

$6 \quad$ A 'forma da expressão' é o meio pelo qual se realiza a obra, por exemplo, por meio de uma expressão alfanumérica, notação musical, palavra falada, imagem etc. A 'língua da expressão' é aquela em que se expressa a obra (International Federation of Library Associations, 2008, p.54).

A 'indicação de responsabilidade', atributo da 'manifestação', compreende um ou mais indivíduos ou grupos responsáveis pela criação ou realização do conteúdo intelectual ou artístico. A 'indicação de edição' é uma palavra ou frase identificada na manifestação que certifica uma diferença no conteúdo ou forma da manifestação. A'data da publicação' representa o ano em que a manifestação foi disponibilizada por uma editora (International Federation of Library Associations, 2008).

O 'identificador do item' é um número ou código associado com o item e serve para diferenciá-lo de qualquer outro na mesma coleção (International Federation of Library Associations, 2008). 


\section{Análise do número do livro e das entidades e atributos do Grupo 1 do modelo FRBR}

A elaboração do número de chamada, para efeito desta análise, deu-se a partir da obra de Machado de Assis, cuja escolha se justifica pela riqueza da fortuna crítica a ela associada. Optou-se pela supressão do número de coleção e o uso do número de classe a partir da 22a edição da CDD (Dewey, 2003). Por se tratar de obra de literatura portuguesa do Brasil, escrita no século XIX, faz-se pertinente atribuir a notação B869.3. Na sequência, seguindo as orientações dadas na tabela Cutter-Sanborn (1962), excetuando-se a separação dos livros a partir de seu tamanho e as obras a que se atribui a classe de biografias, a composição do número do livro será explicitada (Quadro 1).

Quadro 1. Exemplos de Número de chamada.

\begin{tabular}{|c|c|c|}
\hline No & Exemplos selecionados & No de chamada \\
\hline 1 & Assis, Machado de. Dom Casmurro. São Paulo: Ática, 1985. & $\begin{array}{l}\text { B869.3 } \\
\text { A848d }\end{array}$ \\
\hline 2 & $\begin{array}{l}\text { Assis, Machado de. Dom Casmurro: a novel. Tradução Helen Caldwell. Berkeley, Los Angeles: University } \\
\text { of California Press, } 1966 .\end{array}$ & $\begin{array}{l}\text { B869.3 } \\
\text { A848d.lc }\end{array}$ \\
\hline 3 & $\begin{array}{l}\text { Assis, Machado de. Dom Casmurro: a novel. Tradução Helen Caldwell. 2nd. edition. Berkeley, Los Angeles: } \\
\text { University of California Press, } 1971 .\end{array}$ & $\begin{array}{l}\text { B869.3 } \\
\text { A848d.lc } \\
1971\end{array}$ \\
\hline 4 & $\begin{array}{l}\text { Caldwell, Helen. The Brazilian Othello of Machado de Assis: a study of Dom Casmurro. Berkeley, Los } \\
\text { Angeles: University of California Press, } 1960 .\end{array}$ & $\begin{array}{l}\text { B869.3 } \\
\text { A848d.YC }\end{array}$ \\
\hline 5 & Machado, Ubiratã. Dicionário de Machado de Assis. Rio de Janeiro: Academia Brasileira de Letras, 2008. & $\begin{array}{l}\text { B869.3 } \\
\text { A848.Zm }\end{array}$ \\
\hline
\end{tabular}

Fonte: Elaborado pelos autores (2018)

O número do livro para os exemplos acima terá como elemento base a notação de autor composta conforme prescrito na tabela de Cutter-Sanborn para o sobrenome Assis, Machado: A848. Esta escolha é justificada pelo pressuposto de que é de interesse reunir toda a obra de Machado de Assis e a fortuna crítica a ela associada em um mesmo agrupamento.

Na sequência, será elaborada a marca da obra que deriva da primeira letra significativa do título original da obra a ser ordenada: no exemplo 1, a letra d remete à inicial da palavra Dom, primeira letra presente no título Dom Casmurro. No caso das traduções ou obras críticas, é recomendado que se use a indicação da inicial do 'título da obra' na língua original ou da obra criticada, de modo que elas estejam espacialmente agrupadas junto à obra original. A tabela ainda indica, para o caso das traduções, a colocação de um ponto (.) seguido da inicial maiúscula da 'língua da expressão' para a qual o texto foi traduzido e da inicial do sobrenome do tradutor responsável (Cutter, 1962). Nos casos 2 e 3, emprega-se a notação .lc, pois trata-se de tradução para o idioma inglês, realizada por Helen Caldwell. Ainda em relação ao terceiro exemplo, no caso de várias edições de uma mesma obra, representam-se as diversas edições pela indicação do número da edição ou da data de publicação das edições subsequentes à primeira existente na coleção. O exemplo em questão opta pela indicação da edição por meio da colocação da data de publicação (1971) que permite, então, que se distingam as duas edições e, ainda, que a edição de 1966 esteja anteposta na estante à de 1971.

Já para o exemplo 4, relativo a uma crítica sobre Dom Casmurro, é recomendado que se faça uso da notação Y imediatamente após a indicação da primeira letra do 'título da obra' original e, em seguida, registre-se a inicial do sobrenome do crítico em letra minúscula (.Yc - c, pois no exemplo, a crítica é Helen Caldwell). Portanto, embora não seja a obra Dom Casmurro, mas com ela estabeleça uma clara relação associativa, a marca da obra se faz para o título da obra em que se baseia a crítica e não para o título da própria crítica. 
Consoante a mesma lógica, o exemplo 05 explicita as orientações da tabela Cutter-Sanborn (1962) para os dicionários relativos a uma obra ou ao conjunto de obras de um determinado autor. Nesse caso, trata-se de dicionário relativo à obra completa de Machado de Assis, daí a ausência da notação indicativa de um título específico, sendo a notação de autor imediatamente seguida pela indicação da 'forma da obra' (.Z), sucedida da inicial minúscula do sobrenome do autor do dicionário.

Segundo as instruções, tem-se uma notação que se refletirá espacialmente em uma sequência linear da obra original, seguida de imediato de suas traduções e ainda das obras críticas e dos dicionários escritos sobre ela. Desta maneira, o conjunto da obra de um autor pode ser agrupado de modo rigoroso, fazendo com que cada uma de suas obras seja acompanhada de suas traduções e de sua fortuna crítica, sendo ainda seguida pelas publicações críticas e pelos dicionários que se referem à obra como um todo. Como último elemento, em todos estes casos, existindo mais de um 'item,' é possível também individualizá-los por meio da indicação de um número correspondente ao do 'item': 2 para o segundo, 3 para o terceiro, e assim sucessivamente.

Confrontados com os atributos das quatro entidades do Grupo 1 do modelo conceitual FRBR, os números do livro dos cinco exemplos abarcam diferentes atributos presentes em cada uma das entidades. $\mathrm{O}$ atributo 'identificador do item', da entidade 'item', corresponde à totalidade da notação referente ao número de chamada e, portanto, é único para cada item da coleção. Nesta estrutura, no primeiro exemplo, dentro do número do livro, a marca da obra (d) corresponde ao atributo 'título da obra' da entidade 'obra'.

No segundo exemplo, por se tratar de uma tradução para a língua inglesa, os atributos 'título da obra' (d), 'língua da expressão' (.I) e 'indicação de responsabilidade' (c) respectivamente das entidades 'obra', 'expressão' e 'manifestação', foram mobilizados (d.lc). O mesmo ocorre com o terceiro exemplo, em que os atributos 'título da obra' (d), 'língua da expressão' (.I) e 'indicação de responsabilidade' (c) continuaram presentes e o atributo 'data da publicação' (1971) foi adicionado no número do livro para representar uma nova 'expressão' da mesma obra do segundo exemplo.

O quarto e quinto exemplos representam novas 'obras' e os atributos identificados remetem às entidades 'obra' e 'manifestação.' Os atributos presentes no quarto exemplo são 'título da obra', 'forma da obra' e 'indicação de responsabilidade'. Nele, o atributo 'forma da obra' é representado pela indicação de crítica da obra de Dom Casmurro (.Y), enquanto a 'indicação de responsabilidade' é representada pela inicial do sobrenome do tradutor (c). No quinto exemplo, o atributo 'forma da obra' é representado pela indicação de dicionário (.Z) e a 'indicação de responsabilidade'é representada pela inicial do sobrenome do autor (m).

O cotejamento entre os elementos do número do livro e as entidades do Grupo 1 do modelo FRBR aponta para a convergência conceitual entre diferentes processos de Organização da Informação, neste caso, a ordenação de documentos e a catalogação. Assim, não parece gratuito que haja correspondência entre a ordem de apresentação dos elementos componentes do número do livro elaborado para os exemplos analisados e a sequência dos atributos presentes nas entidades 'obra', 'expressão' e 'manifestação', respectivamente.

A fim de atender à necessidade dos usuários e à funcionalidade dos registros, o catálogo estruturado com base nos FRBR visualiza registros bibliográficos e de autoridade como entidades, os elementos desses registros como atributos e as ligações entre os registros e entre os elementos de dados e os registros como relacionamentos (Tillet, 1988). A seguir, com base no trabalho de Moreno (2006), simula-se em ordem alfabética o resultado de uma busca feita pela entidade 'obra' em catálogo FRBRizado com os cinco exemplos levantados para discussão.

Autor: Assis, Machado de

Obra: Dom Casmurro

Forma: texto - Inglês 
Edição:

Título: Dom Casmurro : a novel

Indicação de responsabilidade: by Machado de Assis ; translated and with an introduction by Helen Caldwell.

Imprenta: Los Angeles: University of California Press, 1966

Descrição física: xxi, 269 p. ; 21 cm

Edição: 2nd

Título: Dom Casmurro : a novel

Indicação de responsabilidade: by Machado de Assis ; translated and with an introduction by Helen Caldwell

Imprenta: Los Angeles: University of California Press, 1971

Descrição física: 269 p. ; 21 cm

Forma: texto - Português

Edição:

Título: Dom Casmurro

Indicação de responsabilidade: Machado de Assis

Imprenta: São Paulo: Ática, 1985

Descrição física: 152p.

Autor: Caldwell, Helen

Obra: The Brazilian Othello of Machado de Assis: a study of Dom Casmurro

Forma: texto - Inglês

Edição:

Título: The Brazilian Othello of Machado de Assis: a study of Dom Casmurro

Indicação de responsabilidade: Helen Caldwell

Imprenta: Berkeley, Los Angeles: University of California Press, 1960

Descrição física: vii, 194 p. ; 23 cm.

Autor: Machado, Ubiratã

Obra: Dicionário de Machado de Assis

Forma: texto - Português

Edição:

Título: Dicionário de Machado de Assis

Indicação de responsabilidade: Ubiratã Machado ; [apresentação de Cícero Sandroni]

Imprenta: Rio de Janeiro: Academia Brasileira de Letras, 2008

Descrição física: 375 p. : il., (algumas color.) ; 28 cm

Como é possível observar, em um catálogo FRBRizado, os exemplos 1, 2 e 3 seriam apresentados conjuntamente, de modo similar ao que é possibilitado espacialmente pelo número do livro enquanto elemento constituinte do número de chamada. Expressa-se, destarte, tanto para o processo de ordenação dos registros bibliográficos quanto para o de ordenação de documentos, proximidade entre uma 'obra' e suas 'expressões'. Cabe lembrar que, neste caso, a ordenação dos registros no resultado de uma busca no catálogo em formato 
Machine-Readable Cataloging Record (MARC) se faria verticalmente e em ordem alfabética sem explicitar, conforme colocado acima, um relacionamento derivativo, que é realizado entre itens e as modificações baseadas neste item, como por exemplo as edições, traduções, dramatizações etc. (Tillett, 1988). De igual modo, em nome de uma espacialidade coerente com a proposta de agrupamento de toda a obra de e sobre Machado de Assis, as obras 4 e 5 recebem o mesmo número de classe e notação de autor das demais. Nesses dois últimos exemplos, a autoria não é elemento primário dentro da composição do número do livro e exerce função acessória, já que o autor referenciado pela notação de autor é Machado de Assis, e não os responsáveis intelectuais pela crítica e pelo dicionário em questão. O número do livro transpõe o conceito de ponto de acesso principal, utilizado na catalogação para a escolha da representação principal da obra no catálogo e na elaboração do número do livro para a composição do número de chamada. Ele permanece atribuído a Machado de Assis evidenciando espacialmente o relacionamento entre uma obra e criações realizadas a partir da descrição, crítica ou revisão da obra original.

Assim, a proposta de analisar a estruturação do número de chamada, em especial o número do livro em Cutter, em associação ao modelo conceitual FRBR, permite perceber que a articulação entre obras e suas derivações pode ser realizada não apenas entre os registros, mas também por meio da disposição espacial dos documentos. Como nos lembra Calenge (2009), ordenação de documentos se coloca como modo de leitura de certa coleção e, no caso do número de chamada aqui analisado e cotejado com os FRBR, releva a anterioridade com que contemplou os mesmos princípios de Organização da Informação na estruturação de processos. Neste caso, o número de chamada poderia ser apontado, ainda, como produto documentário cuja FRBRização precoce se fez com base na exploração de conceitos que, embora empregados, não foram explicitados enquanto constituintes fundamentais do número do livro.

\section{Considerações Finais}

A elaboração de sistemas de informação bibliográfica pressupõe a articulação entre os vários processos que compõem a Organização da Informação. A análise acima, ainda que breve e lacunar, permite abrir caminhos que apontam para uma maior compreensão das especificidades e das zonas de interseção entre a catalogação e a ordenação de documentos. Nesse sentido, a análise traz à tona a atualidade do número de chamada enquanto modelo operacionalizável para a ordenação de documentos e, também, como construção elaborada a partir de princípios básicos que representam alto grau de correlação com entidades e atributos do FRBR. Considera-se, ademais, a pertinência de pensar as escolhas dos métodos de ordenação de documentos empregados não apenas quanto à sua disseminação em determinada comunidade, mas quanto à pertinência dos elementos que ela incorpora para a instituição em que se insere, para o público a que destina e aos documentos sobre os quais opera.

O uso do número de chamada em bibliotecas tem potencial para agrupar documentos cujas relações, num primeiro momento, não seriam obviamente lembradas e é precisamente nesta potencialidade que ele pode ser lido enquanto um aliado na FRBRização das coleções, mesmo sendo bastante anterior ao FRBR. A relevância de um catálogo consistente e amigável ao usuário reforça, e não diminui, o valor de uma coleção coerentemente ordenada e, dentro dos vários modelos possíveis de realizar esta disposição, o número de chamada incorpora elementos que parecem especialmente adequados para as coleções exaustivas. Uma apreciação mais criteriosa do uso do número de chamada pode permitir, inclusive, ofertar aos usuários modos de leitura mais propositivos e significativos para a exploração dos conteúdos dos documentos, fomentando sua apropriação e dando relevo às ações dos profissionais.

Cabe ressaltar que a proposta sistematizada por Cutter na virada do século XIX para o XX e alvo desta análise não é a única existente, tampouco a única possível. É recomendável que as instituições façam adaptações nos modelos utilizados de modo a torná-los compatíveis com as demandas que se colocam. Todavia, alterar de modo 
coerente e crítico um modelo exige conhecer seus elementos basilares e os potenciais de uso em relação aos demais processos de Organização da Informação, haja vista o direto vínculo conceitual que une esses processos, mas que, em grande medida, não se encontra explicitado.

Pensar as relações entre os processos implica considerar a historicidade dos princípios que orientam a Organização da Informação. Neste caso, implica colocar em diálogo o número de chamada enquanto produto documentário pensado por Cutter, com o modelo conceitual FRBR, proposto pela IFLA, mas cujos conceitos basilares como a noção de obra e expressão remetem à explicitação de princípios de catalogação colocados ainda no século XIX. Com isso, não se defende a proposição de genealogias ancoradas na ideia de permanência ou linearidade, mas uma mirada conceitual que permita adensar as reflexões que visem compreender os diálogos estabelecidos pelos diferentes processos de Organização da Informação. Por outro lado, avaliar a pertinência dos modelos implica fazer opções que poderão impactar diretamente os modos de acesso aos documentos e favorecer a serendipidade nas coleções, neste caso não meramente acidental, mas catalisada por ações propositadamente realizadas a fim de instigar e munir de fontes seus usuários. Esse tipo de apreciação, por sua vez, pode oportunizar escolhas mais apropriadas pois, sustentadas pela reflexão conceitual, consegue dialogar diretamente com as vivências profissionais que demandem a análise do cotidiano a fim de propor as intervenções necessárias.

\section{Colaboradores}

C.M.A. SILVA e V.S. TOLENTINO contribuíram na concepção e desenho do estudo, análise de dados e redação. C.D. ORTEGA contribuiu com a revisão crítica do artigo.

\section{Referências}

Barden, B.R. Booknumbers: A manual for students, with a basic code of rules. Chicago: American Library Association, 1937. Available from: https://babel.hathitrust.org/cgi/pt?id=mdp. 39015033787162. Cited: Dec. 18, 2017.

Calenge, B. (Coord.). Mettre en oeuvre un plan de classement. Villeurbanne: Presses de l'ENSSIB, 2010.

Cutter, C.A. Explanação das marcas de autor Cutter-Sanborn: tabelas com três algarismos. 2. ed. Rio de Janeiro: Departamento de Imprensa Oficial, 1962.

Cutter, C.A. Explanation of the alphabetic-order marks (threefigure tables). Northampton: Herald Job Print, 1908. Available from: https://archive.org/details/explanationofalp00cuttrich. Cited: Dec. 18, 2017.

Dewey, M. Dewey Decimal Classification and relative index. 22th ed. Albany: Forest Press, 2003. 4v.

Dewey, M. Classification and subject index for cataloguing and arranging the books and the pamphlets of a library. Hartford: Case, Lockwood \& Brainard Company, 1876. Available from: https://archive.org/details/classificationan00dewerich. Cited: Dec. 18, 2017.

International Federation of Library Associations. Study Group on the Functional Requirements for Bibliographic Records. Functional requirements for bibliographic records: Final report. Munich: Saur, 1998. (IFLA UBCIM Publications New Series; v.19). Available from: https://www.fla.org/files/assets/cataloguing/ frbr/frbr.pdf. Cited: Dec. 18, 2017.
International Federation of Library Associations. Study Group on the Functional Requirements for Bibliographic Records. Requisitos funcionais para registros bibliográficos: relatório final. Lisboa: Biblioteca Nacional de Portugal, 2008.

International Federation of Library Associations. Statement of International Cataloguing Principles. 2016. Available from: https://www.ifla.org/files/assets/cataloguing/icp/icp_2016en.pdf. Cited: June 20, 2018

Le Boeuf, P. O admirável mundo novo do FRBR. In: Tillett, B.B. et al. (Ed.). IFLA princípios de catalogação: passos para um código internacional de catalogação, 5.: relatório do Encontro de Peritos da IFLA sobre um Código Internacional de Catalogação, 5., Pretória, África do Sul, 2007. München: K.G. Saur, 2008. p.156-168.

Lehnus, D. J. Notação de autor: manual para bibliotecas. Rio de Janeiro: Brasilart, 1978.

Mann, M. Introduction to cataloging and the classification of books. Chicago: American Library Association, 1930.

Moreno, F.P. Requisitos Funcionais para Registros Bibliográficos - FRBR: um estudo no catálogo da Rede Bibliodata. 2006. 202f. Dissertação (Mestrado em Ciência da Informação) - Universidade de Brasília, Brasília, 2006. Disponível em: http:// repositorio.unb.br/bitstream/10482/2565/1/DISSERTACAO \%20FERNANDA\%20MORENO\%20-\%20UnB.pdf. Acesso em: 18 dez. 2017.

Moreno, F.P.; Márdero Arellano, M.A. Requisitos funcionais para registros bibliográficos FRBR: uma apresentação. Revista 
Digital de Biblioteconomia e Ciência da Informação, v.3, n.1, p.20-38, 2005. Disponível em: https://periodicos.sbu.unicamp. br/ojs/index.php/rdbci/article/view/2052/2182. Acesso em: 18 dez. 2017

Ortega, C.D.; Silva, M.A.S.; Santos, M.N. A ordenação de documentos na atividade bibliotecária. Brasília: Briquet de Lemos, 2016.

Ranganathan, S.R. Prolegomenato Library Classification. 3rd. ed. New York: Asia Publishing House, 1967.

Satija, M.P. Book number and call number. In: Encyclopedia of library and information science. New York: Marcel Dekker, 1990. v.45, p.18-45

Silva, C.M.A. Para uma abordagem contemporânea sobre ordenação de documentos: propostas do século XIX e início do XX. 2016. 230f. Dissertação (Mestrado em Ciência da Informação) - Universidade Federal de Minas Gerais, Belo
Horizonte, 2016. Disponível em: http://www.bibliotecadigital. ufmg.br/dspace/bitstream/handle/1843/BUBD-AMWGPB/ camila_silva___disserta__o_para_uma_abordagem_ contempor_nea_sobre_a__ordena_o_de_documentos. pdf? sequence=1. Acesso em: 18 dez. 2017.

Sordet, Y. Da argila à nuvem: uma história dos catálogos de livros (II Milênio-Século XXI). Livro: Revista do Núcleo de Estudos do Livro e da Edição, n.6, p.23-70, 2016.

Strout, R.F. The development of the catalog and cataloguing codes. Library Quarterly, v.26, n.4, p.254-275, 1956.

Svenonius, E. The intellectual foundation of information organization. Cambridge: MIT Press, 2000.

Tillett, B. Bibliographic relationships in library catalogues. International Cataloguing and Bibliographic Control, v.17, n.1, p.3-6, 1988. 